\title{
PENGARUH GREEN PERCEIVED VALUE TERHADAP GREEN REPURCHASE INTENTION YANG DIMEDIASI OLEH GREEN TRUST
}

\author{
Ni Putu Candradita Revita Sudita ${ }^{1}$ \\ Ni Wayan Ekawati ${ }^{2}$ \\ ${ }^{1,2}$ Fakultas Ekonomi dan Bisnis, Universitas Udayana, Bali, Indonesia \\ e-mail: revitasudita@gmail.com
}

\begin{abstract}
ABSTRAK
Isu mengenai lingkungan telah semakin disadari oleh masyarakat dengan maraknya pemberitaan mengenai pemanasan global. Hal ini mendorong konsumen untuk lebih menghargai produk ramah lingkungan. Penelitian ini bertujuan untuk menjelaskan pengaruh green perceived value terhadap green repurchase intention yang dimediasi oleh green trust produk The Body Shop di kota Denpasar. Jumlah sampel pada penelitian ini sebanyak 120 responden dengan menggunakan teknik purposive sampling. Teknik analisis yang digunakan dalam penelitian ini adalah teknik analisis jalur. Berdasarkan hasil analisis ditemukan bahwa green perceived value berpengaruh positif dan signifikan terhadap green repurchase intention. Green perceived value memiliki pengaruh positif dan signifikan terhadap green trust. Green trust memiliki pengaruh positif dan signifikan terhadap green repurchase intention. Green trust secara signifikan memediasi pengaruh green perceived value terhadap green repurchase intention. The Body Shop sebaiknya lebih intensif dalam memberikan informasi mengenai manfaat yang didapat dari menggunakan produknya serta harus lebih meningkatkan mutu dan kualitas produk.
\end{abstract}

Kata kunci: green marketing, green perceived value, green trust, green repurchase intention.

\begin{abstract}
Environmental issues have been increasingly recognized by the public with the rise of news about global warming. This encourages consumers to better appreciate environmentally friendly products. This study aims to explain the effect of green perceived value on green repurchase intention mediated by green trust products of The Body Shop in Denpasar city. The number of samples in this study were 120 respondents by using purposive sampling technique. The analysis technique used in this research is path analysis technique. Based on the analysis result, it was found that green perceived value had positive and significant effect on green repurchase intention. Green perceived value has a positive and significant effect on green trust. Green trusts have a positive and significant influence on green repurchase intention. Green trusts significantly mediate the effect of green perceived value on green repurchase intention. The Body Shop should be more intensive in providing information about the benefits derived from using the product and must further improve the quality and quality of the product.
\end{abstract}

Keywords: green marketing, green perceived value, green trust, green repurchase intention. 


\section{PENDAHULUAN}

Isu mengenai lingkungan telah semakin meningkat disadari oleh masyarakat dunia semakin sadar akan pentingnya pelestarian lingkungan semakin meningkat, dengan maraknya pemberitaan mengenai global warming saat ini. Adanya global warming, laju kerusakan lingkungan mengalami peningkatan terus-menerus. Kondisi lingkungan yang selalu berubah-ubah dengan adanya penipisan lapisan ozon, bencana-bencana, pemanasan global atau lebih dikenal dengan istilah global warming yang berdampak pada iklim, dan perkembangan penyakit akibat dari penggunaan bahan-bahan kimia makanan dan polusi udara (Putra, 2015). Perhatian masyarakat terhadap keramahan lingkungan yang semakin meningkat, mendorong perusahaan untuk sadar akan pentingnya menjaga lingkungan dengan membuat produk ramah lingkungan (Widyantari \& Suparna, 2016).

Masyarakat saat ini tampak lebih sadar lingkungan, memahami pentingnya hidup sehat, dan menunjukkan meningkatnya kebutuhan produk berbasis alam. Konsumen yang memiliki kesadaran tinggi terhadap lingkungan akan memilih produk-produk yang ramah lingkungan walaupun harganya relatif lebih mahal (Ekawati et al., 2017). Pola hidup masyarakat di zaman global, modern, dan super kompetitif sekarang ini membuat pembangunan dan kehidupan menjadi sangat eksploitatif terhadap sumber daya alam, sehingga dampak yang dihasilkan akan mengancam kehidupan lingkungan (Putri \& Suparna, 2014). Ancaman kerusakan lingkungan ini telah mendorong wirausaha maupun masyarakat untuk beralih pada produk yang ramah lingkungan (Ekawati et al., 2017). Konsumen percaya bila konsumen menyukai dan membeli brand yang berorientasi lingkungan, pelaku 
industri akan terdorong untuk melakukan perubahan pada produk, kemasan, atau bahkan periklanan di media massa (Atmoko \& Setyawan, 2013). Banyaknya dampak negatif yang terjadi apabila pemanasan global tidak ditangani secara sigap dan kurangnya kesadaran masyarakat akan pentingnya lingkungan sekitar, membuat sebagian masyarakat mulai sadar dan khawatir akan dampak-dampak negatif yang ditimbulkan akibat terjadinya pemanasan global, itu sebabnya kini sebagian masyarakat mulai merubah pola pikir konsumen akan pentingnya untuk lebih mmeperhatikan lingkungan, mulai dari memisahkan sampah plastik dengan sampah yang tidak dapat didaur ulang, menanam pohon disekitar rumah, tidak menggunakan kantong plastik saat berbelanja di swalayan, serta mulai menggunakan produk-produk yang ramah lingkungan (Martusa, 2009).

Kesediaan konsumen dalam mengambil keputusan untuk mengkonsumsi atau membeli produk hijau (produk ramah lingkungan) merupakan salah satu tindakan nyata manusia untuk menekan laju kerusakan lingkungan (Lee, 2009). Konsumen beradaptasi dengan situasi saat ini dan mempunyai kesadaran tinggi terhadap lingkungan, konsumen akan memilih produk-produk ramah lingkungan walaupun harganya relatif lebih mahal (Nilasari, 2016). Bukti yang mendukung peningkatan lingkungan ekologikal ini adalah meningkatnya individu yang rela membayar lebih produk-produk yang ramah lingkungan (Aninda, 2008).

Perkembangan dunia bisnis saat ini, maka tingkat persaingan semakin berkembang dalam pemenuhan kebutuhan manusia. Peran pemasaran sangat penting dalam suatu perusahaan. Pemasaran tidak lepas dari sisi konsumen, dimana konsumen sebagai alat ukur dalam menentukan keberhasilan suatu produk 
atau jasa. Peran pemasaran yang tidak lain bertujuan untuk mengetahui kebutuhan konsumen, dimana kebutuhan konsumen akan bergerak dinamis sesuai dengan perkembangan sehingga para pemasar harus peka membaca setiap perubahan selera konsumen. Terkait dengan isu lingkungan tersebut, perusahaan dapat mempertimbangkan sebagai peluang untuk memuaskan kebutuhan dan keinginan konsumen. Perusahaan dapat mengaplikasikan isu-isu lingkungan dalam aktivitas pemasaran sehingga menimbulkan fenomena baru dalam dunia pemasaran yang berupa konsep pemasaran hijau atau yang dikenal dengan green marketing (Putripeni et al., 2014).

Green Marketing dapat didefinisikan sebagai semua kegiatan yang dirancang oleh perusahaan dalam rangka memenuhi kebutuhan manusia dengan mengurangi dampak yang merugikan bagi lingkungan. Green Marketing juga dapat disebut sebagai proses yang bertujuan untuk pengamanan alam atau lingkungan dengan mendorong konsumen untuk menggunakan atau mengkonsumsi produk yang tidak membahayakan lingkungan dan sebagai upaya dalam proses pembangunan lingkungan yang berkelanjutan (Pillai, 2013).

Green marketing adalah segala aktivitas yang akan dilakukan oleh sebuah perusahaan untuk meminimalisir adanya kerusakan lingkungan (Bhatnagar \& Himani, 2012). Green marketing merupakan proses perencanaan bauran pemasaran yang memanfaatkan berubahnya kesadaran konsumen terhadap produk atau jasa yang lebih ramah lingkungan (Stevanie, 2016). Implementasi strategi pemasaran berwawasan lingkungan memiliki banyak bentuk, seperti meminimalkan polusi yang dihasilkan selama proses produksi, penggunaan bahan 
daur ulang sebagai bahan baku produksi dan menyangkut material lainnya seperti kemasan produk, pelabelan, karton pembungkus, serta melakukan aktivitas sosial atau donasi yang berorientasi pada kelestarian lingkungan (Manongko, 2011).

Implementasi strategi pemasaran berwawasan lingkungan (Green marketing) ini juga menerapkan standar internasional atau lebih dikenal dengan ISO-14000. Internasional Organization For Standardization (ISO) mengembangkan suatu seri standar internasional untuk ekolabel (ISO 14020 -ISO 14024) (Risyamuka, 2015). Konsumen membeli barang dan jasa untuk memenuhi berbagai kebutuhan dan keinginan. Pemenuhan kebutuhan dan keinginan secara langsung berhubungan dengan kegunaan (benefit) yang dapat diberikan oleh barang dan jasa tersebut. Apabila konsumen merasa barang dan jasa yang ditawarkan suatu perusahaan tersebut mampu untuk memenuhi kebutuhan dan keinginan konsumen, maka hal tersebut dapat meningkatkan repurchase intention.

Repurchase intention merupakan keputusan konsumen tentang membeli lagi sebuah produk dari perusahaan yang sama dengan menghitungkan situasi dan kondisinya (Hellier, 2003). Repurchase intention adalah kecenderungan perilaku membeli dari konsumen pada suatu produk barang atau jasa, didasarkan pada pengalaman yang telah dilakukan di masa lampau (Suryana, 2013). Green repurchase intention merupakan prilaku pembelian hijau dimana konsumen merespon positif terhadap kualitas produk ramah lingkungan dan berniat untuk melakukan kunjungan kembali atau menggunakan kembali produk ramah lingkkungan di perusahaan yang sama (Lam et al., 2016). Terjadinya kepuasan dan ketidakpuasan pasca pembelian konsumen terhadap suatu produk akan 
mempengaruhi perilaku selanjutnya. Jika konsumen puas, maka akan menunjukkan kemungkinan yang lebih tinggi untuk membeli kembali produk tersebut (Kotler \& Keller, 2012).

"A specific type of purchase intentions is repurchase intentions, which reflect whether we anticipate buying the same product or brand again" mengatakan bahwa bentuk spesifik dari niat pembelian adalah niat pembelian ulang, yang mencerminkan harapan untuk membeli ulang produk atau merek yang sama, customer repeat purchase adalah tujuan yang paling penting bagi keberhasilan perusahaan dan mungkin konsep yang paling penting dalam pemasaran (Lam, 2016). Pembelian ulang (repurchase) bersifat bervariasi tergantung pada tingkat ketahananya (durability) suatu produk. Untuk produk yang tidak tahan lama (non-durables), pembelian kembali diartikan sebagai tindakan membeli lagi setelah pembelian pertama atau trial. Sedangkan untuk produk yang tahan lama (durables), diartikan sebagai kesediaan konsumen untuk membeli ulang atau memberikan paling tidak satu saran kepada orang lain untuk melakukan pembelian (Lee, 2011). Akibatnya, perusahaan memfokuskan kembali upaya perusahaan dalam mempertahankan konsumen yang sudah ada atau membuat konsumen membeli kembali, daripada berfokus sepenuhnya dalam usaha mendapatkan pelanggan baru (Hiller et al., 2003).

Repurchase intention dapat digunakan untuk memprediksi apakah konsumen bisa menjadi pelanggan jangka panjang dan membawa keuntungan yang stabil bagi perusahaan atau tidak (Lee, 2011). Repurchase intention biasanya didapat dari hasil survey pelanggan saat ini yang menilai kecenderungan mereka 
untuk membeli merek yang sama, produk atau jasa yang sama, dari perusahaan yang sama. Customer repurchase intention juga sering ditentukan oleh perceived value (Cronin, 2000).

Persepsi nilai adalah penilaian keseluruhan konsumen dari suatu produk berdasarkan persepsi apa yang diterima dan diberikan (Petrick, 2003). Green Percieved value didefinisikan sebagai suatu manfaat yang diterima konsumen dari mengkonsumsi produk hijau yang berdampak baik bagi konsumen atau menjadi suatu keuntungan yang didapat dari mengkonsumsi produk hijau yang merupakan nilai yang dirasakan dari produk tersebut (Putra, 2015). Perceived value didasarkan pada evaluasi teliti yang dilakukan oleh customer terhadap suatu produk atau jasa (Zeithaml, 1998), dan dapat menyatakan sebagai penukaran antara nilai yang dirasakan (perceived value) dan biaya yang dirasakan (perceived costs) (Jen \& Hu, 2003). Perceived value yang dinikmati oleh customer melebihi perceived costs maka customer repurchase intention cenderung tinggi (Cronin, 2000). Niat membeli dan sikap loyal dari konsumen adalah hal terpenting bagi sebuah perusahaan untuk mempertahankan eksistensinya dan agar dapat bertahan dalam persaingan dengan menjaga konsumen yang ada dan menarik perhatian konsumen baru.

Perusahaan harus memberikan tingkat pelayanan yang baik dan tenaga kerja yang berkualitas supaya memberi kesan pengalaman positif kepada konsumen dan pada akhirnya dapat tercipta rasa kepuasan dan percaya (trust) dari konsumen terhadap perusahaan. 
Penilaian yang dirasakan pada produk hijau juga sangat penting untuk meningkatkan kepercayaan hijau. Kepercayaan mempunyai peran penting pada keputusan konsumen pada pembelian ulang (Kaveh et al., 2012). konsumen yang sudah merasa puas terhadap merek tertentu akan memunculkan suatu komitmen kepercayaan, yang ditunjukan dengan menggunakan produk dari perusahaan yang sama terus menerus tanpa mempertimbangkan produk dari perusahasaan pesaing (Azfal et al., 2010). Kepercayaan merupakan salah satu elemen yang penting dalam suatu hubungan yang sehat, sebagai dasar bagi hubungan personal, sebagai syarat bagi kerja sama dan sebagai dasar bagi stabilitas institusi sosial dan juga dalam pasar (Egan, 2004). Green trust adalah kesediaan menggunakan beberapa spesifik terpercaya baik jasa atau merek yang diyakini memiliki dampak yang positif terhadap lingkungan (Chen \& Chang, 2012).

Salah satu sektor industri yang saat ini cukup banyak menggunakan sistem green marketing adalah perusahaan dari sektor industri kecantikan. Pelopor green marketing di Indonesia sendiri yang sudah terkenal dalam industri kosmetik adalah The Body Shop. Menghadapi isu pemanasan global yang sangat mencekam saat ini atau sering disebut dengan global warming masyarakat mulai berpikir untuk mencoba mengkonsumsi produk ramah lingkungan (Wati \& Ekawati, 2016). Masyarakat Indonesia sendiri pemilihan kosmetik adalah sesuatu yang mudah namun sulit, artinya para konsumen dihadapkan pada banyaknya pilihan yang menyebabkan mereka bingung untuk memilih, karena jika salah memilih dapat berakibat bagi kesehatan, keindahan kulit dan wajah mereka. 
Produk utama The Body Shop ialah produk perawatan tubuh (wajah, badan, rambut, dan kosmetik, parfum (cologne, parfum wanita, parfum pria, lilin atau aromaterapi), dan aksesoris (sikat badan, peralatan perawatan kuku, dan lain lain). Namun apa yang ditawarkan oleh The Body Shop sedikit berbeda karena menawarkan produk dengan bahan-bahan alami, ramah lingkungan dan no animal testing (produk - produk The Body Shop tidak pernah diuji cobakan pada binatang) (www.thebodyshop.co.id diunduh 2017).

Salah satu pesaing The Body Shop yang menawarkan produk sejenis adalah The Face Shop. Kemunculan produk kosmetik asal Korea, The Face Shop membuat pesaingan di dunia kosmetik semakin gencar, sebagai pendatang baru di Indonesia yang sudah terkenal di sebagian negara Asia Timur seperti Jepang dan Korea dengan pemilihan aktor laki-laki sebagai bintang dengan menawarkan kualitas kulit putih, halus, dan bersih dengan The Face Shop White Tree salah satu produk andalannya (femaledaily.com diunduh 2017). Mengetahui hal ini The Body Shop mulai memperhatikan green marketing yang diterapkan, untuk memenangkan persaingan. Namun tidak semua perusahaan memiliki kemampuan cukup untuk melakukan strategi ini. Jika perusahaan ingin berhasil mengadopsi green marketing, perusahaan harus menginterpretasikan konsep green marketing ke dalam aspek kegiatan pemasaran rutin (Chen \& Chang, 2012). Keberhasilan produk hijau dapat diukur dari pengembangan produk yang mampu memberikan manfaat bagi konsumennya dan memiliki tanggung jawab terhadap lingkungan (Ekawati et al., 2017).

Berdasarkan paparan sebelumnya maka penelitian ini akan mengkaji 
bagaimana upaya perusahaan kosmetik The Body Shop meningkatkan green repurchase intention terhadap pelanggan kosmetik The Body Shop dengan adanya pengaruh green perceived value dan mengetahui bagaimana peran green trust sebagai variabel mediasi green perceived value terhadap green repurchase intention.

Perilaku pembelian pada umumnya didorong dengan adanya nilai yang dirasakan dan biaya yang dikeluarkan konsumen dalam melakukan perilaku pembelian hijau. Konsumen merasakan keuntungan dan kepuasan terhadap produk ramah lingkungan maka konsumen akan sadar mempunyai keinginan untuk membeli produk ramah lingkungan (Kaufmann, 2012). Repurchase intention adalah hasil dari proses evaluasi terhadap suatu produk atau jasa. Ketika seorang konsumen melakukan evaluasi terhadap produk atau jasa yang dikonsumsi, mereka cenderung untuk membeli produk atau jasa yang dirasa memberikan nilai lebih bagi diri mereka (customer perceived value) (Assael, 1998). Adanya kemungkinan konsumen untuk membeli kembali dari perusahaan yang sama jika mereka berpikir bahwa apa yang mereka terima (benefit) lebih berharga dari apa yang mereka berikan (sacrifice) (Cronin et al., 2000).

Menurut penelitian Giffar (2016) dan Puspitaningrum (2006) menyatakan terdapat hubungan positif antara perceived value denganrepurchase intention. Penelitian yang dilakukan Kusdyah (2012) dan Aris (2016) menyatakan bahwa, persepsi nilai memiliki pengaruh yang positif signifikan dengan niat membeli kembali dan pemasar harus meningkatkan persepsi konsumen tentang nilai produk hijau perusahaan untuk semakin meningkatkan niat membeli kembali. 
$\mathrm{H}_{1}$ : Green perceived value berpengaruh positif dan signifikan terhadap green repurchase intention.

Berdasarkan penelitian Aris (2016) dan Chen dan Chang (2012) bahwa, terdapat hubungan positif antara green perceived value dan green trust. Nilai yang dirasakan sangat penting untuk menimbulkan kepercayaan konsumen. Jika nilai yang dirasakan konsumen pada suatu produk atau jasa tersebut tinggi, maka kepercayaan konsumen akan meningkat terhadap suatu produk atau jasa tersebut. Niat yang dirasakan penting dalam mempengaruhi kepercayaan pelanggan, karena kesadaran lingkungan yang lebih menonjol saat ini, telah banyak dieksplorasi nilai ynag dirasakan karena memiliki efek positif pada kinerja pemasaran (Chen \& Chang, 2012).

Penelitian yang dilakukan oleh Pratama (2014) green perceived value berpengaruh positif dengan green trust pada lampu Philips LED di Surabaya. Menurut penelitian yang dilakukan oleh Lam et al. (2016), Giffar (2016), Pratama (2015), Eid (2011), Putra (2015), Chen dan Chang (2012) menyatakan terdapat hubungan yang positif antara green perceived value terhadap green trust. Melalui nilai yang dirasakan pada produk hijau, memberikan manfaat lebih bagi konsumen, maka akan meningkatkan kepercayaan konsumen pada produk ramah lingkungan.

$\mathrm{H}_{2}$ : Green perceived value berpengaruh positif dan signifikan terhadap green trust.

Kepercayaan merupakan salah satu faktor utama yang mempengaruhi pembelian (Kamtarin, 2012). Kepercayaan mengacu pada keyakinan individu bahwa konsumen akan berperilaku berdasarkan harapan. Disimpulkan bahwa 
repurchase intention dipengaruhi oleh kepercayaan konsumen, jika konsumen memiliki kepercayaan yang baik terhadap produsen, perusahaan maupun produk dan jasa maka konsumen akan memiliki minat beli yang tinggi (Chen \& Chang, 2012). Kepercayaan terjadi ketika satu pihak percaya kepada tindakan pihak lain. Kepercayaa pada produk hijau ini akan mempengaruhi perilaku pembelian hijau (Chen, 2013). Penelitian yang dilakukan oleh Pratama (2014) serta penelitian Prasetyo terhadap situs OLX.co.id (2015) yang menyatakan bahwa, kepercayaan mempengaruhi secara positif dan signifikan minat beli ulang seorang konsumen dan berperan sebagai variabel intervening. Menurut penelitian Lam et al. (2016) menyatakan terdapat hubungan positif antara green trust dengan green repurchase intention. Handono et al. (2015) menyatakan bahwa kepercayaan berpengaruh positif dengan niat pembelian kembali.

$\mathrm{H}_{3}$ : $\quad$ Green trust berpengaruh positif dan signifikan terhadap green repurchase intention.

Nilai yang dirasakan konsumen dapat meningkatkan kepercayaan konsumen, tingkat nilai tinggi yang dirasakan konsumen dapat meningkatkan kepercayaan konsumen (Kim et al., 2008). Manfaat yang dirasakan didefinisikan bahwa sejauh mana konsumen percaya pada pembelian suatu produk akan meningkatkan kinerja transaksinya atau pembelian ulang kembali akan terjadi (Lee et al., 2011). Jika nilai suatu produk, harapan, keyakinan, tinggi, maka kepercayaan konsumen pada suatu produk akan meningkat, serta dapat membangun niat pembelian konsumen terhadap suatu produk atau jasa (Kwok et al., 2015). 
Dalam penelitian Chen dan Chang (2012), menyatakan bahwa green trust memediasi penuh hubungan antara green perceived value dengan green purchase intention pada produk ramah lingkungan. Selanjutnya Putra dan Suryani (2012) menyatakan secara positif green trust memediasi green perceived value dengan green purchase intention pada produk organik. Semakin banyak manfaat yang diperoleh konsumen mengenai suatu produk, makan akan menimbulkan kepercayaan terhadap produk tersebut, oleh karena itu hal tersebut akan mempengaruhi perilaku pembelian ulang. Semakin besar kepercayaan konsumen, maka peluang konsumen untuk melakukan pembelian ulang akan semakin besar.

$\mathrm{H}_{4}$ : Pengaruh green perceived value terhadap green repurchase intention mampu dimediasi oleh green trust.

\section{METODE PENELITIAN}

Penelitian ini ialah penelitian asosiatif yang bertujuan untuk mengetahui hubungan antar dua variabel atau lebih (Sugiyono, 2013:11). Penggunaan metode ini untuk membuktikan dan menjelaskan hubungan pengaruh variabel green perceived value terhadap variabel green trust dan variabel green perceived value terhadap variabel green repurchase intention, kemudian pengaruh variabel green trust terhadap variabel green repurchase intention, serta pengaruh variabel green perceived value terhadap variabel green repurchase intention dimediasi oleh variabel green trust.

Lokasi penelitian dilakukan di perusahaan The Body Shop yang merupakan salah satu perusahaan green marketing di Denpasar dengan beberapa alasan, diantaranya yaitu karena pertumbuhan ekonomi di Denpasar cukup tinggi dan 
didukung daya beli masyarakat yang juga cukup baik serta pengetahuan masyarakat kota Denpasar khususnya kalangan anak muda dan tertarik akan sebuah brand juga sudah memiliki standar yang cukup baik dibandingkan dengan kota-kota lain di Bali (denpasarkota.go.id diunduh 2016). Sedangkan objek penelitiannya adalah green repurchase intention yang dipengaruhi oleh variabel green perceived value dan green trust.

Pada penelitian ini, variabel penelitian dan indikator variabel penelitian disajikan pada Tabel 1.

Tabel 1.

Indikator Variabel

\begin{tabular}{|c|c|c|c|c|}
\hline Variabel & No & Variabel & Indikator & Sumber \\
\hline Eksogen & 1 & $\begin{array}{c}\text { Green } \\
\text { Percived } \\
\text { Value } \\
\text { (X1) }\end{array}$ & $\begin{array}{ll}\text { a) Benefit for customer } \\
\\
\text { b) } \\
\text { b) Environmental concern }\left(\mathrm{X}_{1.2}\right) \\
\text { c) Standard of quality }\left(\mathrm{X}_{1.3}\right) \\
\text { d) Price }\left(\mathrm{X}_{1.4}\right)\end{array}$ & $\begin{array}{c}\text { Chen dan Chang } \\
\text { (2012) }\end{array}$ \\
\hline Mediasi & 2 & $\begin{array}{l}\text { Green Trust } \\
\text { (M) }\end{array}$ & $\begin{array}{ll}\text { a) } & \text { Minat transaksional } \\
& \left(\mathrm{M}_{1.1}\right) \\
\text { b) } & \text { Minat referensial }\left(\mathrm{M}_{1.2}\right) \\
\text { c) } & \text { Minat preferensial }\left(\mathrm{M}_{1.3}\right) \\
\text { d) } & \text { Minat eksploratif }\left(\mathrm{M}_{1.4}\right)\end{array}$ & $\begin{array}{l}\text { Ferdinand } \\
\text { (2002) }\end{array}$ \\
\hline Endogen & 3 & $\begin{array}{c}\text { Green } \\
\text { Repurchase } \\
\text { Intention } \\
\text { (Y1) }\end{array}$ & $\begin{array}{l}\text { a) Organic claim }\left(\mathrm{Y}_{1.1}\right) \\
\text { b) Reputation }\left(\mathrm{Y}_{1.2}\right) \\
\text { c) Environmental performance } \\
\quad\left(\mathrm{Y}_{1.3}\right) \\
\text { d) Environmental commitments } \\
\quad\left(\mathrm{Y}_{1.4}\right)\end{array}$ & $\begin{array}{c}\text { Chen dan Chang } \\
\text { (2013) }\end{array}$ \\
\hline
\end{tabular}

Pada Tabel 1 dilakukan pengklasifikasian variabel-variabel penelitian. Variabel terikat dalam penelitian ini adalah Green Repurchase Intention (Y) yang diukur dengan menggunakan empat indikator yaitu minat transaksional, minat referensial, minat preferensial, dan minat eksploratif. Variabel bebas dalam penelitian ini adalah Green perceived value (X) yang diukur dengan 
menggunakan empat indikator yaitu Benefit for costumers, Environmental concern, Standard of quality, dan Price. Sedangkan variabel mediasi dalam penelitian ini adalah Green trust (M) yang diukur dengan menggunakan empat indikator yaitu Organic claim, Reputation, Environmental performance, dan Environmental commitments.

Jenis data yang digunakan dalam penelitian ini adalah data kuantitatif berupa jumlah responden. Data kualitatif pada penelitian ini berupa sejarah perusahaan The Body Shop. Sedangkan sumber data yang digunakan dalam penelitian ini adalah sumber primer berupa identitas pembelian produk The BodyShop, jawaban dari reponden terhadap setiap butiran pernyataan dalam kuesioner, serta data target penjualan dan pertumbuhan produk The Body Shop. Sumber sekunder berupa data yang diperoleh dari tinjuan pustaka melalui literarur, jurnal-jurnal terkemuka, dan situs internet yang dapat memberikan informasi yang sesuai dengan masalah penelitian ini.

Populasi dalam penelitian ini adalah pelanggan perusahaan kosmetik yang menggunakan produk The Body Shop di Kota Denpasar. Pengumpulan sampel menggunakan metode purposive sampling. Penelitian ini menggunakan 12 indikator berarti sampel yang diperlukan minimal adalah 60 (12x5) dan maksimal 120 (12x10), sehingga dengan menggunakan estimasi berdasarkan jumlah parameter diperoleh ukuran sampel sebesar 60 - 120 responden. Maka jumlah sampel yang digunakan dalam penelitian ini sebanyak 120 responden.

Metode pengumpulan data yang digunakan dalam penelitian ini adalah kuesioner dengan metode angket, yakni penyebaran kuesioner melalui cara yaitu 
memberikan kuesioner yang berupa pertanyaan-pertanyaan kepada responden. Penyebaran kuesioner, kuisioner juga disebar melalui google form dengan tujuan untuk mempermudah menemukan responden yang sesuai. Penelitian ini juga menggunakan wawancara langsung dengan karyawan dari The Body Shop untuk mendapatkan data dan informasi tambahan dari pihak manajemen.

Penelitian ini menggukanan teknik analisis jalur (path analysis). Namun sebelum melakukan uji analisis jalur, terlebih dahulu peneliti melakukan uji asumsi klasik yang terdiri dari uji normalitas, uji multikolinearitas, dan uji heteroskedastisitas.

\section{Gambar 1. Model Analisis Jalur}

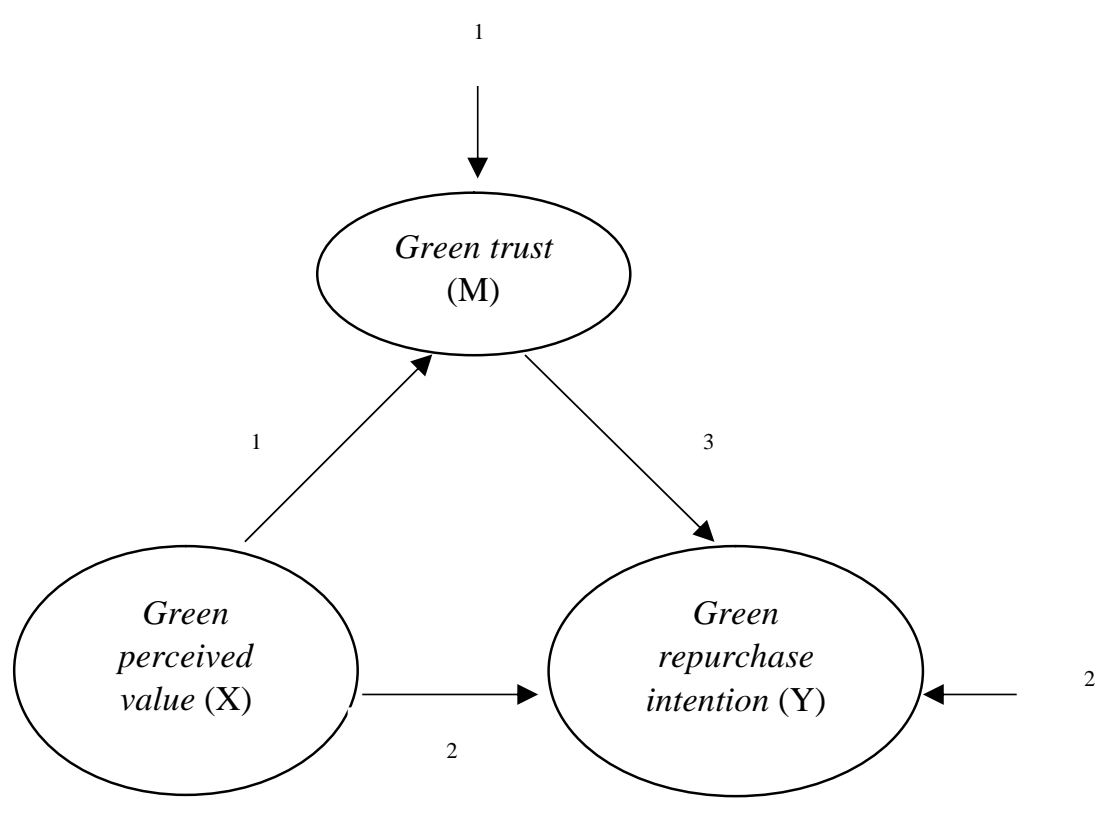

Pengaruh Green perceived value (X) terhadap Green Repurchase Intention (Y) ditunjukkan oleh koefisien jalur $\beta_{2}$, pengaruh langsung Green perceived value (X) terhadap Green trust (M) diperlihatkan oleh koefisien jalur $\beta_{1}$, dan pengaruh Green Repurchase Intention (Y) terhadap Green trust (M) diperlihatkan oleh 
koefisien jalur $\beta_{3}$. Pengaruh tidak langsung Green perceived value (X) terhadap Green trust (M) diperoleh dengan mengalikan $\beta_{1}$ dan $\beta_{2}$.

Model persamaan struktural diatas juga dapat dinyatakan dalam bentuk persamaan atau diagram jalur sehingga disebut juga dengan sistem persamaan simultan atau model struktural sebagai berikut :

$$
\begin{aligned}
& \mathrm{M}=\beta_{1} \mathrm{X}+\mathrm{e} \\
& \mathrm{Y}=\beta_{1} \mathrm{X}+\beta_{2} \mathrm{M}+\mathrm{e} \\
& \mathrm{Y}=\text { green repurchase intention } \\
& \mathrm{X} \quad=\text { green perceived value } \\
& \mathrm{M} \quad=\text { green trust } \\
& \beta_{1}, \beta_{2}, \beta_{3} \quad=\text { koefisien regresi variabel } \\
& \mathrm{e}=\text { error }
\end{aligned}
$$

\section{Uji Mediasi (Uji Sobel)}

Untuk menguji signifikansi peran mediasi variabel Green trust digunakan rumus Sobel. Berdasarkan diagram jalur pengaruh tidak langsung, maka dapat dihitung standar error koefisien a dan b ditulis dengan $S_{a}$ dan $S_{b}$, besarnya standar error tidak langsung (indirect effect) $\mathrm{S}_{\mathrm{ab}}$ dihitung dengan rumus berikut ini:

$$
S_{\mathrm{ab}}=\sqrt{b^{2} S_{a}^{2}+a^{2} S_{b}^{2}+S_{a}^{2} S_{b}^{2}}
$$

Keterangan:

$\mathrm{a}=$ koefisien regresi dari variabel independen $(\mathrm{X})$ terhadap variabel mediasi $(\mathrm{M})$.

$\mathrm{s}_{\mathrm{a}}=$ standar error dari a.

$\mathrm{b}=$ koefisien regesi dari variabel mediasi $(\mathrm{M})$ terhadap variabel dependen $(\mathrm{Y})$ $\mathrm{s}_{\mathrm{b}}=$ standar error dari $\mathrm{b}$

Apabila hasil nilai perhitungan $Z>1,96$ (tingkat kepercayaan 95 persen), maka variabel intervening dianggap secara signifikan memediasi hubungan antara 
variabel eksogen dan variabel endogen

\section{HASIL DAN PEMBAHASAN}

\section{Karakteristik Responden}

Dari hasil penelitian yang dilakukan terhadap pembeli di The Body Shop yang berjumlah 120 orang dapat diketahui gambaran tentang karakteristik responden yang meliputi dua aspek yaitu jenis kelamin, dan usia.

Tabel 2.

\section{Karakteristik Responden}

\begin{tabular}{ccccc}
\hline No & Variabel & Klasifikasi & $\begin{array}{c}\text { Jumlah } \\
\text { (orang) }\end{array}$ & $\begin{array}{c}\text { Persentase } \\
(\boldsymbol{\%})\end{array}$ \\
\hline \multirow{2}{*}{1} & Jenis & Laki-Laki & 2 & 1,7 \\
& Kelamin & Perempuan & 118 & 98,33 \\
& & Jumlah & $\mathbf{1 2 0}$ & $\mathbf{1 0 0}$ \\
2 & \multirow{2}{*}{2} & 18-28 Tahun & 96 & 80 \\
& Usia & 25-34 Tahun & 24 & 20 \\
\hline & & Jumlah & $\mathbf{1 2 0}$ & $\mathbf{1 0 0}$ \\
\hline
\end{tabular}

Sumber: Data primer diolah, 2018

Tabel 2 menunjukan karakteristik responden dapat dilihat berdasarkan pengelompokkan jenis kelamin, jenis kelamin perempuan mendominasi dalam penelitian ini dengan presentase sebesar 98,33 persen. Berdasarkan usia responden yang memiliki usia 18-28 Tahun mendominasi dalam penelitian ini dengan persentase sebesar 80 persen. Hasil ini mengindikasikan bahwa produk The Body Shop lebih banyak diminati oleh konsumen wanita dan di usia rentang 18-28 tahun.

\section{Hasil Uji Validitas}

Uji validitas bertujuan untuk menguji sejauh mana intrumen yang digunakan dalam penelitian ini mampu mengukur variabel yang telah ditetapkan oleh 
peneliti. Suatu instrumen yang valid ditunjukkan dengan $\mathrm{r}$ Pearson Correlation skor total $\geq 0,30$. Berikut adalah hasil uji validitas dari penelitian ini.

Tabel 3.

Hasil Uji Validitas

\begin{tabular}{ccccc}
\hline No. & Variabel & Instrumen & $\begin{array}{c}\text { Pearson } \\
\text { Correlation }\end{array}$ & Keterangan \\
\hline & & X.1 & 0,950 & Valid \\
1. & \multirow{2}{*}{ Green Perceived Value (X) } & X.2 & 0,923 & Valid \\
& & X.3 & 0,954 & Valid \\
& & X.4 & 0,939 & Valid \\
& & M.1 & 0,739 & Valid \\
2. & Mreen Trust (M) & M.2 & 0,769 & Valid \\
& & M.3 & 0,877 & Valid \\
& & Y.1 & 0,886 & Valid \\
& & Y.2 & 0,939 & Valid \\
3. & Green Repurchase Intention $($ Y) & Y.3 & 0,940 & Valid \\
& & Y.4 & 0,875 & Valid \\
& & & & Valid \\
\hline
\end{tabular}

Sumber: Data primer diolah, 2018

Berdasarkan Tabel 3 menunjukkan bahwa seluruh instrumen variabel penelitian berupa Green Perceived Value, Green Trust dan Green Repurchase Intention telah memenuhi syarat uji validitas yang dimana nilai skor total Pearson Correlation masingmasing instrumen berada diatas 0,30 maka instrumen layak digunakan menjadi alat ukur variabel-variabel tersebut.

\section{Hasil Uji Reliabilitas}

Uji reliabilitas mampu menunjukan sejauh mana instrument dapat dipercaya dan diharapkan. Nilai suatu instrument dikatakan reliable apabila nilai Alpha Cronbach $\geq 0,6$. Hasil uji reliabilitas dapat dilihat pada Tabel 4 .

Tabel 4.

Uji Reliabilitas

\begin{tabular}{llcc}
\hline No. & \multicolumn{1}{c}{ Variabel } & Cronbad'sAlpha & Keterangan \\
\hline 1. & Green Perceived Value $(\mathrm{X})$ & 0,956 & Reliabel \\
2. & Green Trust $(\mathrm{M})$ & 0,836 & Reliabel \\
3. & Green Repurchase Intention $(\mathrm{Y})$ & 0,915 & Reliabel \\
\hline
\end{tabular}

Sumber: Data primer diolah, 2018 
Tabel 4 menampilkan hasil uji reliabilitas pada masing-masing variabel berada pada titik diatas 0,60 yang ditunjukkan pada hasil Cronbach's Alpha, maka dapat dikatakan seluruh instrumen telah memenuhi syarat reliabilitas.

\section{Hasil Uji Normalitas}

Uji normalitas menggunakan uji Kolmogorov-Smirnov, dengan uji ini dapat diketahui data yang digunakan berdistribusi normal atau tidak. Apabila Sign t hitung $>0.05$, maka data tersebut berdistribusi normal dan begitu juga sebaliknya (Santoso, 2001).

Berdasarkan hasil analisis pada Tabel 5 menunjukkan bahwa nilai signifikansi sebesar 0,119 dan 0,113> $\alpha=0,05$ maka dapat disimpulkan bahwa data terdistribusi secara normal.

Tabel 5.

Hasil Uji Normalitas Struktur 1 dan Struktur 2

\begin{tabular}{llrr}
\hline & & $\begin{array}{c}\text { Unstandardized } \\
\text { Residual }\end{array}$ & $\begin{array}{c}\text { Unstandardized } \\
\text { Residual }\end{array}$ \\
$\mathrm{N}$ & Mean & 120 & 120 \\
Normal Parameters & .0000000 & .0000000 \\
& Std. Deviation & .42983097 & .52967601 \\
Most Extreme Differences & Absolute & .139 & .109 \\
& Positive & .139 & .109 \\
& Negative & -.114 & -.105 \\
Kolmogorov-Smirnov Z & & 1.124 & 1.199 \\
Asymp. Sig. (2-tailed) & & .119 & .113 \\
\hline Sumber: Data primer diolah, 2018 & &
\end{tabular}

\section{Hasil Uji Multikolinieritas}

Uji multikolinieritas digunakan untuk mengetahui apakah antara variabel bebas terjadi multikolinieritas atau tidak. Uji yang digunakan yaitu dengan melihat nilai VIF (Varian Inflation Factor) dan Tolerance pada proses regresi 
biasa, jika keduanya mendekati 1 atau besaran VIF kurang dari 10 maka model tidak terkena multikolinieritas.

Tabel 6.

Hasil Uji Multikolinieritas

\begin{tabular}{clcc}
\hline No & \multicolumn{1}{c}{ Variabel } & Nilai Tolerance & Nilai VIF \\
\hline 1 & Green Perceived Value & 0,248 & 4,037 \\
2 & Green Trust & 0,248 & 4,037 \\
\hline
\end{tabular}

Sumber: Data primer diolah, 2018

Hasil uji multikolinearitas pada Tabel 6 menunjukan bahwa nilai tolerance Green Perceived Value dan Green Trust $>0,1$ dan nilai VIF $<10$. Jadi dapat disimpulkan bahwa tidak terdapat gejala multikolinearitas.

\section{Hasil Uji Heteroskedasitas}

Uji Heteroskedastisitas bertujuan untuk menguji apakah dalam model terjadi ketidaksamaan varian atau residual satu pengamatan ke pengamatan lainnya. Jika tingkat signifikan lebih besar dari 0,05 maka terjadi heteroskedastisitas.

Tabel 7.

\section{Hasil Uji Heteroskedastisitas}

\begin{tabular}{clcl}
\hline No & \multicolumn{1}{c}{ Variabel } & Sig. & Keterangan \\
\hline 1 & Green Perceived Value & 0,355 & Bebas Heteroskedastisitas \\
2 & Green Trust & 0,284 & Bebas Heteroskedastisitas \\
\hline
\end{tabular}

Sumber: Data primer diolah, 2018

Tabel 7 memperlihatkan tingkat signifikansi tiap variabel $>0,05$ sehingga dapat disimpulkan bahwa model terbebas dari gejala heteroskedastisitas.

\section{Hasil Analisis Jalur}

Berdasarkan hasil perhitungan koefisien regresi, nilai error dan determinasi total, maka dapat disusun diagram model analisis jalur seperti pada gambar 2 . sebagai berikut. 


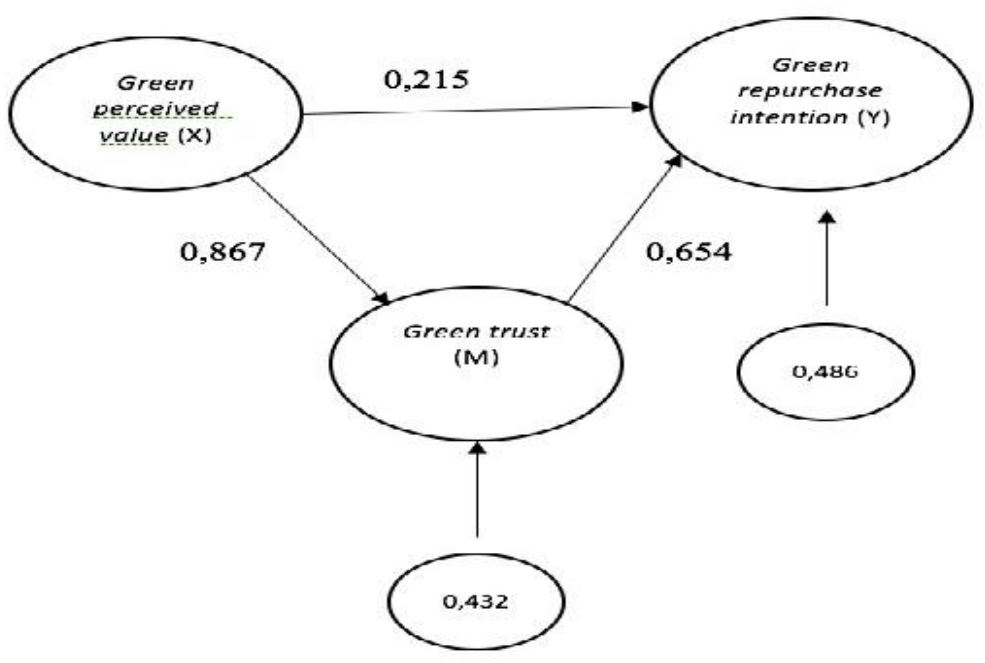

Gambar 2. Diagram Model Analisis Jalur

Sumber: Hasil pengolahan data penelitian, 2017

Dari diagram jalur tersebut dapat dikalkulasi besaran pengaruh langsung, tidak langsung, serta pengaruh total antar variabel. Kalkulasi pengaruh antar variabel-variabel penelitian dapat diringkas dalam Tabel 8.

Tabel 8.

Pengaruh Langsung, Pengaruh Tidak Langsung Green Perceived Value (X), Terhadap Green Trust (M) Green Repurchase Intention (Y)

\begin{tabular}{ccrr}
\hline Pengaruh variabel & Pengaruh langsung & $\begin{array}{c}\text { Pengaruh tidak } \\
\text { langsung melalui M }\end{array}$ & Pengaruh Total \\
\hline $\mathrm{X} \rightarrow \mathrm{M}$ & & & 0,867 \\
$\mathrm{M} \rightarrow \mathrm{Y}$ & 0,867 & 0,567 & 0,654 \\
$\mathrm{X} \rightarrow \mathrm{Y}$ & 0,654 & & 0,782 \\
\hline Sumber $:$ Data primer diolah, 2018 & 0,215 & &
\end{tabular}

Tabel 8 menunjukkan Green Perceived Value memiliki pengaruh langsung terhadap Green Trust sebesar 0,867 dan pengaruh langsung dari Green Perceived Value terhadap Green Repurchase Intention sebesar 0,215 sedangkan pengaruh tidak langsung nya sebesar 0,567 sehingga memiliki pengaruh total sebesar 0,782 . Green Trust memiliki pengaruh langsung terhadap Green Repurchase Intention sebesar 0,654 . 
Pada perhitungan nilai koefisien determinasi total didapatkan sebesar 0,955, maka kesimpulannya adalah $95,5 \%$ variabel Green Repurchase Intention konsumen The Body Shop dipengaruhi oleh Green Perceived Value dan Green Trust, sedangkan sisanya 4,5\% dipengaruhi oleh faktor lain yang tidak dimasukkan dalam model penelitian atau diluar model penelitian.

\section{Uji Sobel}

Uji sobel digunakan untuk menguji signifikansi variabel Green Trust sebagai variabel mediasi dalam hubungan antara variabel Green Perceived Value dan Green Repurchase Intention. Uji Sobel yang dilakukan, hasil kalulasi Z = 5,67 >1,96 dengan tingkat signifikansi $0.000<0.05$ yang berarti Green Trust secara signifikan memediasi hubungan antara Green Perceived Value terhadap Green Repurchase Intention. Sehingga hipotesis keempat diterima.

\section{Pengaruh green perceived value terhadap green repurchase intention}

Berdasarkan hasil pada Tabel 8 Green Perceived Value memiliki nilai Beta sebesar 0,215 dan nilai Sig. sebesar 0,032, maka dapat dikatakan $\mathrm{H}_{1}$ diterima karena nilai Sig. 0,032 <0,05. Kesimpulannya adalah bahwa Green Perceived Value memiliki pengaruh positif dan signifikan terhadap Green Repurchase Intention, dengan kata lain semakin meningkat Green Perceived Value konsumen The Body Shop, maka semakin tinggi tingkat Green Repurchase Intention konsumen The Body Shop. Sehingga hipotesis pertama diterima.

\section{Pengaruh green perceived value terhadap green trust}

Berdasarkan hasil pada Tabel 8 Green Perceived Value memiliki nilai Beta sebesar 0,867 dan nilai Sig. sebesar 0,000, maka dapat dikatakan $\mathrm{H}_{2}$ diterima 
karena nilai Sig. 0,000<0,05. Kesimpulannya adalah Green Perceived Value berpengaruh positif dan signifikan terhadap Green Trust dengan kata lain semakin tinggi Green Perceived Value maka Green Trust konsumen The Body Shop akan semakin meningkat. Sehingga hipotesis kedua diterima.

\section{Pengaruh green trust terhadap green repurchase intention}

Berdasarkan hasil pada Tabel 8 Green Trust memiliki nilai Beta sebesar 0,753 dan nilai Sig. sebesar 0,000, maka dapat dikatakan $\mathrm{H}_{3}$ diterima karena nilai Sig. $0.000<0,05$. Kesimpulannya adalah bahwa Green Trust memiliki pengaruh positif dan signifikan terhadap Green Repurchase Intention, dengan kata lain apabila Green Trust meningkat maka Green Repurchase Intention konsumen The Body Shop akan semakin meningkat. Sehingga hipotesis ketiga diterima.

\section{Pengaruh green perceived value terhadap green repurchase intention dimediasi oleh green trust}

Hasil pengujian menunjukkan nilai $\mathrm{Z}$ pada uji Sobel sebesar 5,67 atau lebih besar dari 1,96, sehingga $\mathrm{H}_{4}$ diterima dan $\mathrm{H}_{0}$ ditolak. Hal ini berarti Green Trust secara signifikan mampu memediasi hubungan antara Green Perceived Value terhadap Green Repurchase Intention. Semakin baik Green Trust yang didasarkan pada Green Perceived Value maka peningkatan Green Repurchase Intention akan semakin baik, begitu pula sebaliknya.

\section{SIMPULAN DAN SARAN}

Berdasarkan hasil pembahasan penelitian yang telah dilakukan, maka dapat disimpulkan bahwa Green perceived value berpengaruh positif dan signifikan terhadap green trust. Green trust berpengaruh positif dan signifikan terhadap green repurchase intention. Green perceived value berpengaruh positif dan 
signifikan terhadap green repurchase intention. Green trust berpengaruh positif dan signifikan dalam memediasi pengaruh green perceived value terhadap green repurchase intention. Sedangkan saran yang dapat diberikan diantaranya perusahaan sebaiknya lebih memperhatikan harga yang ditawarkan agar sesuai dengan kualitas yang didapatkan konsumen dari produk The Body Shop. Selain itu perusahaan sebaiknya lebih gencar untuk mensosialisasikan mengenai manfaat yang diperoleh dari produk The Body Shop kepada masyarakat khususnya di Kota Denpasar. Diharapkan bagi peneliti selanjutnya dapat memperluas ruang lingkup penelitian dengan pelanggan yang tersebar di berbagai wilayah, baik dalam skala regional maupun nasional. Peneliti selanjutnya juga dapat mengubah objek penelitian serta mempertimbangkan penggunaan variabel lain sehingga dapat memperkaya informasi yang diperoleh guna menciptakan dan meningkatkan green repurchase intention.

\section{REFERENSI}

Adji, J., dan Semuel, H. 2014. Pengaruh Statisfactions dan Trust Terhadap Minat Beli Konsumen Di Starbucks The Square Surabaya. Jurnal Manajemen Pemasaran Petra, 2 (1), 1-10.

Afzal, H., Khan, M. A., Rehman, K. Ur., Ali, I. dan Wajahat, S. (2010) "Consumer's Trust in tehe Brand: Can It Be Built Through Brand Reputation, Brand Competence and Brand Predictability". Journal Internasional Bussiness Research, 3 (1), 44-45.

Akbar, W., Hassan, S., Khurshid, S., and Niaz, M. 2014. Antecedents Affecting Customer's Purchase Intentions towards Green Products. Journal of Sociological Research, 5 (1), 1948-5468.

Ali, A., Khan, A. A., Ahmed, I. 2011. Determinants of Pakistani Consumers Green Purchase Behavior: Some Insights from a Developing Country. International Journal of Business and Social Secience, 2 (3), 217-226.

Aninda, L., Lia dan Ferry, Tema Atmaja. 2008. Pengaruh Kesadaran Lingkungan Pada Niat Beli Hijau: Studi Perilaku Konsumen Terhadap Pembelian 
Kosmetik Ramah Lingkungan. Tesis. Fakultas Ekonomi Universitas Bengkulu.

Atmoko, Waluyo Budi \& Setyawan, Didi. 2013. Green Marketing: Memperkuat Daya Saing Merek Melalui Green Brand Equity. Proceeding Seminar Nasional Dan Call For Papers Sancall, ISBN: 978-979-636-147-2

Bhatnagar, Vidushi \& Himani, Grewal. 2012. An Environmental Protection Tool: Green Marketing and Its Effect On Consumer Behavior. International Journal of Emerging Research in Management and Technology, 3 (2), 1923.

Chen, Y. S. 2010. The driver of green brand equity: green brand image, green satisfaction, and green trust. Journal of Business Ethics, 9 (3), 307- 319.

Chen, Y. S., \& Chang, C. H. 2012. Enhance Green Purchase Intentions: The Roles of Green Perceived Value, Green Perceived Risk, and Green Trust. Management Decision, 50 (3), 502-520.

Chen, Y. S., and Chang, S. H. 2013. Greenwash and green trust: the mediation effects of green consumer confusion and green perceived risk. Journal of Business Ethics, 114, 489-500.

Cronin, J. Joseph. 2000. Assessing the Effects of Quality, Value, and Customer Satisfaction on Consumer Behavioral Intentions in Service Environments. Journal of Retailing, 76 (2), 193-218.

Ekawati, N. W., Kertiyasa, N. N., Giantari, G. A. K., \& Sariyathi, N. K. 2017. Ecopreneurship and Green Innovation for the Success of New Spa Products. Journal of Business and Retail Management Research, 11 (3), 13-16.

Giffar, Davinindya. 2016. Peran Iklan, Brand Image, Price, Trust, Dan Perceived Value Terhadap Repurchase Intention Traveloka. Jurnal Ilmiah Mahasiswa FEB. 4(1), 22-26.

Hellier, Phillip K., et al. 2003. Customer repurchase intention: A general structural equation model. European Journal of Marketing, 37 (11/12), 1762-1800.

Kaufmann, H. R., Panni, M. F. A. K., \& Orphanidou, Y. 2012. Factor Affecting Consumers Green Purchasing Behavior: An Integrated Conceptual Framework. Journal Amfiteatru Economic, 14 (31), 34-40 .

Kim, C., Zhao, W., \& Yang, K. H. 2008. 2013. An Empirical Study On The Integrated Framework Of e-CRM In Online Shopping: Evaluating The Relationships Among Perceived Value, Satisfaction, And Trust Based On 
Customers Perspectives. Journal Of Electronic Commerce In Organizations, 6 (3), 1-19.

Kotler, Philip., and Keller, K. L. 2008. Manajemen Pemasaran. Edisi 13. Jilid 1. Alih Bahasa: Bob Sabran. Jakarta: PT Indeks.

Kusdyah, Ike. 2012. Persepsi Harga, Persepsi Merek, Persepsi Nilai, Dan Keinginan Pembelian Ulang Jasa Clinic Kesehatan (Studi Kasus Erha Clinic Surabaya). Jurnal Manajemen Pemasaran, 7 (1), 5-11.

Kwok, M. L. J., Wong, M. C. M., \& Lau, M. M. 2015. Examining How Enviromental Concern Affects Purchase Intention: Mediating Role Of Perceived Trust And Moderating Role Of Perceived Risk. Contemporary Management Research, 11 (2), 143-152.

Lam, A. Y.C., Lau, M. M., \& Cheung, R. 2016. Modelling The Relationship Among Green Perceived Value, Green Trust, Satisfaction, And Repurchase Intention Of Green Products. Contemporary Management Research, 12 (1), 47-60.

Lee, K. 2009. Gender differences in Hong Kong adolescent consumers' green purchasing behavior. The Journal of Consumer Marketing, 26 (2), 87- 96.

Lee, J., Park, D. H., \& Han, I. 2011. The Different Effects Of Online Consumer Reviews On Consumers Purchase Intentions Depending On Trust In Online Shopping Malls: An Advertising Perspective. Internet Research, 21 (2), 187-206.

Manongko, A. A. C. 2011. Green Marketing Dan Pengaruhnya Terhadap Keputusan Pembelian Melalui Minat Membeli Produk Organik (Studi Pada Pelanggan Produk Organik Di Kota Manado). Tesis Program Studi Magister Manajemen Universitas Brawijaya Malang.

Martusa, 2009. Peranan Environmental Accounting Terhadap Global Warming.Jurnal Akuntansi, 1 (2), 164-179.

Nilasari, N. P. H., dan Kusuma,. N. M. W. 2016. Peran dan sikap dalam memediasi pengaruh kepedulian lingkungan terhadap niat beli kosmetik hijau merek the body shop. E-Journal Universitas Udayana, 5 (1), 121148.

Palwa, Aryanto. 2014. Pengaruh Green Marketing Terhadap Keputusan Pembelian Yang Dimediasi Minat Beli (Studi Pada Pelanggan The Body Shop Di Plaza Ambarukmo Yogyakarta).Jurnal Ilmiah Fakultas Ekonomi Universitas Negeri Yogyakarta 3 (1), 36-42.

Pillai, S. 2013. Profilling Green consumers Based On Their Purchase Behavior. International Juornal of Information, Bussines, And Management, 5 (3), 
$37-41$.

Pratama, M. A. 2014. Pengaruh Green Perceived Value, Green Perceived Risk, Dan Green Trust Terhadap Green Purchase Intention Lampu Philips LED Di Surabaya. Jurnal Ilmiah Mahasiswa Universitas Surabaya, 3(1) 5-8.

Putra, I. P. A. S. S., dan Suryani, A. 2015. Peran Green Trust Memediasi Green Perceived Value Terhadap Green Purchase Behavior Pada Produk Organik. E-Journal Universitas Udayana, 4 (10), 3015-3036.

Putri, Y., dan Suparna, G. 2014. Peran kebiasaan membaca label dalam memediasi pengaruh variabel demografi terhadap niat membeli produk hijau merek Natur-E Di Kota Denpasar. E-Journal Universitas Udayan, 3 (4), 975-987.

Putripeni, M.P., Suharyono., Andriani, K. 2014. Pengaruh Green Marketing Terhadap Citra Merek Dan Keputusan Pembelian (Studi Pada Konsumen The Body Shop Mall Olympic Garden Malang). Jurnal Administrasi Bisnis, 10 (1), 8-12.

Risyamuka., I.K., dan Kastawan, M. 2015. Pengaruh Green Marketing Terhadap Keputusan Pembelian Produk Hijau di Restoran Sari Organik Ubud. EJurnal Manajemen Universitas Udayana, 4 (2), 12-16.

Saputri, Marheni E. dan Tutut Ratna Pranata. 2014. Pengaruh Brand image Terhadap Kesetiaan Pengguna Smartphone Iphone. Jurnal Sosioteknologi, 13 (3), 21-25.

Shaputra, Rizky Kharismawan. 2013. Penerapan Green marketing Pada Bisnis Produk Kosmetik. Jurnal JIBEKA, 7 (3), 47-53.

Sugiyono. 2014. Metode Penelitian Bisnis. Bandung : Alfabeta

Suryana, Popo., dan Dasuki, E. S. 2013. Analisis Faktor Yang Mempengaruhi Keputusan Pembelian Dan Implikasinya Pada Minat Beli Ulang. Trikonomika Journal Universitas Pasundan. 12 (2), 190-200.

Widyantari, N. K. S., dan Suparna, I. G. 2014. Peran Tingkat Pendidikan Memoderasi Citra Merek Dengan Preferensi Merek Lampu Philips LedDi Kota Denpasar. E-Jurnal Manajemen Unud, 5 (5), 2828-2830.

Zeithaml, Valarie A. 1988. Consumer Perceptions of Price, Quality, and Value: A Means-End Model and Synthesis of Evidence. Journal of Marketing, 2 (7), 2- 22 . 